\author{
KATEŘINA PRAŽÁKOVÁ \\ Jihočeská univerzita v Českých Budějovicích \\ E-Mail: katerina.prazakova@gmail.com
}

\title{
DAS WETTEIFERN ZWISCHEN KATHOLIKEN UND PROTESTANTEN UM DAS KRAKAUER STADTZENTRUM IN DER ZWEITEN HÄLFTE DES 16. JAHRHUNDERTS
}

Die Studie ${ }^{1}$ behandelt Fälle, in denen die Auseinandersetzung der Konfessionen um Einfluss in der Stadt Krakau in Gewalt ausartete ${ }^{2}$. Es wird der Verlauf der Konflikte zwischen Katholiken und Protestanten in Krakau untersucht. Das Hauptaugenmerk ist dabei auf die wichtige Umbruchsperiode von den siebziger bis zur Mitte der neunziger Jahre des 16. Jahrhunderts gerichtet. Während am Anfang dieser Etappe protestantische Kirchen und Gruppen von vielen einflussreichen Ma-

1 Die Studie entstand im Rahmen der Tätigkeit des Forschungszentrums Die Habsburger in der Geschichte der Böhmischen Ländern in der frühen Neuzeit an der Philosophischen Fakultät der Südböhmischen Universität in Budweis und des Projekts der Projektagentur der Tschechischen Republik Geschichte der Kommunität. Bilder. Symbole und Performationen der spätmittelalterlichen und frühneuzeitlichen Stadt (1400-1700), Projektnummer 14-25417S.

2 Zum Problem der Anwendung von Gewalt gegen religiöse Opponenten: W. Cavanaugh, Myth of Religious Violence. Secular Ideology and the Roots of Modern Conflict, (2009); I. Hryniewicz, Wołanie na tumult. Prolegomena do badan nad przemoca w stosunkach międzywyznaniowych w Rzeczypospolitej w XVI i XVI wieku, „Acta Universitatis Lodziensis. Folia Litteraria Polonica“', 21 (2013), S. 67-95. 
gnaten unterstützt wurden und die Katholiken befürchteten, ein neu erwählter König könne sich der Reformation zuwenden, verloren in den neunziger Jahren des 16. Jahrhunderts die Protestanten immer mehr an Einfluss und man ahnte bereits, dass sich der Katholizismus in Polen-Litauen in Zukunft siegreich durchsetzen werde ${ }^{3}$.

Bei der Erforschung der religiös motivierten Tumulte konzentrieren wir uns zunächst auf die Frage, ob sich bei den Übergriffen der einen oder der anderen Seite ein bestimmtes Muster wiederholte. Wir untersuchen, wodurch die Scharmützel meist provoziert wurden, wie sie verliefen und was ihre Urheber erreichen wollten. Besonders die Absichten, die hinter diesen Tumulten standen, sind von großer Bedeutung. Obwohl die Krakauer Tumulte auf den ersten Blick ganz zufällig und chaotisch erscheinen, wird schon bei der ersten Untersuchung der Quellen sichtbar, dass wenigstens einige von ihnen in der Tat sorgfältig geplant worden waren. Besonders die Katholiken scheinen bei den Unruhen ziemlich zielstrebig vorgegangen zu sein, wobei sie den Andersgläubigen nicht nur ein Ärgernis bereiteten, sondern diese gezielt aus der Innenstadt verdrängten, indem sie ihren Sakralraum plünderten und zerstörten. Die These, im Krakau des 16. Jahrhunderts sei eine anscheinend chaotische Gewalt dazu übergegangen, den gegnerischen sakralen Raum zu erobern, ist genau zu überprüfen und verspricht, auch für andere Orte interessante Ergebnisse zu bringen.

\section{BELIEBTE ANGRIFFSZIELE}

Die Spannungen zwischen der katholischen und protestantischen Lehre sowie die damit verbundenen persönlichen Streitigkeiten fanden im Krakauer Gebiet vereinzelt schon seit den fünfziger Jahren des 16.

3 Wichtige zusammenfassende Werke über diese Periode der polnischen Geschichte: J. Tazbir, Dzieje polskiej tolerancji, (1973); ders., Piotr Skarga. Szermierz kontrreformacji, (1962); ders., Reformacja, kontrreformacja, tolerancja, (1997). 
Jahrhunderts einen gewaltsamen Ausbruch. Einen der ersten Vorfälle löste der Kastellan von Chełm Jan Boner ${ }^{4}$ aus, als er am 23. März 1556 betrunken mit seinen Freunden und Verwandten in die Marienkirche am Krakauer Hauptplatz einfiel. Sie verspotteten und schüchterten die Geistlichen ein, die dort zum Stundengebet der Matutine versammelt waren, und beschädigten etliche Bilder sowie Votive auf dem Grabmal des heiligen Stanislaus ${ }^{5}$. Am 12. Februar 1557 griffen wiederum die Brüder Hieronim und Jakub Myszkowski ${ }^{6}$ zwei Priester auf der Straße an und schlugen ihnen mit einem Knüppel auf Mund und Zähne ${ }^{7}$. Ein ähnlicher Angriff endete im Jahre 1568 sogar mit einem Todesfall. Als der Adelige Thomas Tarnawski und seine Begleiter mit dem Priester Stanisław Grot im Studenteninternat stritten, sollen sie ihm mehrmals so heftig auf den Kopf geschlagen haben, dass der Priester an den Verletzungen starb ${ }^{8}$. 1570 kam es wiederum zu Scharmützeln in zwei

4 Jan Boner war zu dieser Zeit lutherisch, später konvertierte er zum Kalvinismus. $\mathrm{Zu}$ seinem Lebenslauf inklusive den Glaubensstreitigkeiten s. M. Hanik, Trzy pokolenia z rodu Bonerów, (1985), S. 49-58.

5 ,[...] ebriosi venientes tumultus quosdam clamores, opprobria et subsannationes ipsis vicariis exhibuerunt et excitarunt, imagunculasque et tabellas epithaphiorum ad tumbam Santi Stanislai, patroni gloriosi pendentes, aliquot decerpserunt, confregerunt et extra templum abiecerunt“. Die Edition des Protokolls des Krakauer Kapitels vom 23. Dezember 1556 in: Materiały do dziejów reformacji w Krakowie. Zaburzenia wyznaniowe w latach 1551-1598, hg. v R. Żelewski, (Materiaty Komisji Nauk Historycznych 6, 1962), Nr. 3, S. 4.

6 Es handelte sich um Kalvinisten, die Brüder von Stanisław Myszkowski, der Wojewode von Krakau. Deren Genealogie auf den Webseiten: Genealogia dynastyczna (URL: http://genealogia.grocholski.pl/gd/osoba.php?id=028385, aufgerufen am 12.11.2016).

7 „[...] Hieronimum Myszkowski, qui die praedicta cum alio fratre suo Iacobo Myszkowski et aliis complicibus ex castro sub horam 23-am temulentus forsan descendendo eosdemque presbyteros ante ingressum portae castrensis visos, in eos, seu honorabilem Iacobum violenti manu invasit atque irruit primum verbis duris, contumeliosis et turpi increpatione affecit, mox illi clavam ferream in os inflixit, dentesque simul et labra illi comminuit, similique insuper vulnera et honorabili Hieronimo inflixit [...]“: Materialy do dziejów reformacji, Nr. 4, S. 5.

8 „[...] consanguineorumque et propinquorum ipsius olim Stanislai Grot pro- 
Klöstern. Am 10. Mai 1570 fiel Jan Palczowski mit seinem Geleit in die Ordenskirche der Franziskaner ein, um die Mönche zu verprügeln, die dort Gebete sangen. Während des heftigen Zusammenstoßes, der darauffolgte, starben angeblich etliche Ordensleute und Studenten, die ihnen zur Hilfe kamen ${ }^{9}$. Am 13 . Oktober 1570 versuchten wieder einige bewaffnete Adelsleute mit ihren Dienern in die Klausur der Norbertinerinnen einzudringen. Sie stießen jedoch auf einen solchen Widerstand, dass dabei sogar einer der Angreifer getötet wurde ${ }^{10}$.

Zusammenfassend kann man von der Periode vor dem Jahr 1574 sagen, dass etliche streitsüchtige protestantische Adelige zahlreiche unterschiedliche Angriffsziele im Auge hatten, wobei sie ihre, einem gewöhnlichen Priester übergeordnete Stellung sowie die Hilfe von zahlreichen Dienern ausnützten. Die Katholiken dagegen hielten sich in dieser Zeit eher zurück. In den Quellen wurden nur eine Revancheattacke auf die Diener von Stanisław Myszkowski ${ }^{11}$ sowie ein Aufruhr

testatum est per nobilem Thomam Tarnawski ac eiusdem certos coadiutores [...], qui consilio et auxilio per se et famulos suos necis illius sunt participes, eo tempore, videlicet feria quinta post festum Sancti Michaelis Archangeli proxime praeterit[um] [30 IX] invaden[tes] ipsum in bursam Iuristarum in platea Castrensi Cracoviae sitam, in qua ipse olim Stanislaus Grot manebat, [...] primum in eum impetu violento manu armata facto, timore Dei postposito et iure paceque communi spret[is], predicto olim Stanislao Grot violenter illata. A quibus vulneribus sic uti preafertur in caput per praefatum Thomam Tarnawski ei illatis, praedictus olim Stanislaus Grot mortuus est". Die Edition von der Klage des Krakauer Bischofs: ebenda, Nr. 16, S. 16.

9 Die Edition vom Protokoll der Sitzung des Krakauer Kapitels in: ebenda, Nr. 18, S. 18.

$10,[\ldots]$ quod tametsi non ita pridem per nonullos malevolos assertos nobiles in claustris ipsius monasterii Zwierzynecensis manu armata ex insidiis fuisset violenter invasus atque ipsemet etiam cum multis hominibus monasterii sui subditis et servitoribus violentiam defendentibus, percussus et enormiter vulneratus, protunc prorsus inermis, dissuasione tantum litis charitativa humana et verbali, ac ad pacem cohortatione, uti dicebat, armatus“: Ebenda, Nr. 19, S. 19. Zur Stellung der Klöster in der Reformationszeit: Orden und Klöster im Zeitalter von der Reformation und katholischer Reform 1500-1700, hg. v. F. Jürgensmeier, R. E. Schwerdtfeger, 1 (2005).

11 Materialy do dziejów reformacji, Nr. 6, S. 6. Die Katholiken stritten mit den Dienern von Stanisław Myszkowski am 7. April 1557, also kurz nach dem Verprügeln 
vor der Allerheiligenkirche erwähnt, in der ein Protestant eine zur Ehe gezwungene Katholikin heiratete ${ }^{12}$. Nach dem Jahr 1574 änderte sich jedoch die Situation wesentlich. Während die Protestanten weiterhin oft katholische Geistliche und Studenten angriffen, richteten die Katholiken ihren Zorn vorwiegend gegen drei Örtlichkeiten, die in den letzten Jahren der Regierung des polnischen Königs Sigismund II. August (1520-1572) entstanden waren ${ }^{13}$.

Die erste Örtlichkeit war ein kalvinistischer Friedhof, der 1569 in der östlichen Vorstadt hinter dem Nikolaus-Tor (Brama Mikołajska) errichtet worden war ${ }^{14}$. Bis zu dieser Zeit wurden die Krakauer Protestanten meist im Dorf Chełm bestattet, also etwa $8 \mathrm{~km}$ vom Stadtzentrum Krakaus entfernt ${ }^{15}$. Auch ihre Gottesdienste fanden in den fünfziger und sechziger Jahren des 16. Jahrhunderts außerhalb der Stadtmauern statt. Dies änderte sich, als die Kalvinisten 1570 das Steinhaus, genannt Bróg, in der St.-Johannes-Straße kauften ${ }^{16}$, das später zu einem be-

der beiden katholischen Geistlichen, an dem ein Onkel von Stanisław Myszkowski beteiligt war, und was wohl von dem anderen mächtigen Onkel, der auch Stanisław hieß, bagatellisiert und vertuscht wurde. Zur Bedeutung des Geschlechtes Myszkowski für die Reformation: G. Schramm, Der polnische Adel und die Reformation, (1965), S. 32 u. 51.

12 Uchańsciana czyli Zbiór dokumentów, wyjaśniających życie i działalność Jakóba Uchańskiego arcybiskupa gnieznieńskiego, legata urodzonego, Królestwa Polskiego prymasa i pierwszego księcia, 1581, hg. v. T. Wierzbowski, 3 (1890), S. 238-239.

13 Zur Religionspolitik Königs Sigismund II. August: A. Dybkowska, Zygmunt August, (2003), S. 64-68; A. Sucheni-Grabowska, Zygmunt August. Król polski i wielki książę litewski, (2010), S. 389-415.

14 Die Abschrift des Königsprivilegiums vom 8. August 1569 in: Kronika zboru ewangelickiego krakowskiego, w której erekcja zboru tego, przywileje, kaznodzieje albo słudzy Boży, starsi zborowi, różne prześladowania, zboru zburzenia, i wiele innych pamiętnych rzeczy przypominaja się i opisują. Przez X. Wojciecha Wegierskiego, hg. v. M. Pawelec, (2007), S. 64-65.

15 Ebenda, S. 9.

16 Ebenda, S. 16; R. Żelewski, Akta i relacje dotyczace zburzenia zboru kalwińskoluterańskiego w Krakowie w r. 1574, „Teki archiwalne“, 2 (1954), S. 109-137, hier $110-111$. 
vorzugten Angriffsziel der Katholiken wurde. Im Jahre 1572 erhielten die Reformierten die Erlaubnis vom König, Bróg in ein Gebetshaus umzubauen ${ }^{17}$. Nach dem Consensus von Sandomir ${ }^{18}$ benutzten sie es zusammen mit Lutheranern, denen sie den ersten Stock überließen. Die mehrheitlich auftretenden einflussreicheren Kalvinisten behielten dagegen das Erdgeschoss. Den beiden Konfessionen diente das Haus Bróg nicht nur als Gebetshaus, sondern auch als Versammlungs- und Beratungsort, Schule, Bibliothek und Depot für Wertsachen. Die Lage dieses Zentrums der Kalvinisten und Lutheraner war recht günstig, es befand sich im Bezirk der reichen Patrizier ganz nahe dem Hauptplatz $^{19}$.

Während das Gebetshaus Bróg sowie der protestantische Friedhof seit ihrem Entstehen in den Quellen zu den Stadtkonflikten oft vorkamen, trat das dritte Objekt zunächst nicht in Erscheinung. Es handelte sich um das Gebetshaus der Antitrinitarier (der Polnischen Brüder), das am Ende der sechziger Jahre in der Spitalstrasse errichtet worden war $^{20}$. Da die Antitrinitarier unter anderem nicht daran glaubten, dass Jesus Christus Gottes Sohn sei, wurde ihre Lehre nicht nur von den Katholiken, sondern auch von anderen protestantischen Bewegungen

17 Die Abschrift des Königsprivilegiums vom 2. Mai 1572 in: Kronika zboru ewangelickiego krakowskiego, S. 66-68.

18 K. Długosz-Kurczabowa, Konfesja Sandomierska, (2001).

19 Die St.-Johannes-Straße beginnt am Hauptplatz Krakaus und führt direkt in nördliche Richtung bis zur ehemaligen Stadtmauer. Es befanden sich in ihr traditionell Häuser einflussreicher Magnaten und reicher Kaufleute. Im 16. Jahrhundert war es zum Beispiel die Familie Boner oder der Sekretär des Königs Justus Ludwik Deciusz (URL: https://pl.wikipedia.org/wiki/Ulica_\%C5\%9Bw._Jana_w_Krakowie, aufgerufen am 25.11.2016).

20 In der älteren Historiografie wird behauptet, dass die Arianer später in die St.-Stephans-Straße umzogen: H. Merczyng, Zbory i senatorowie protestanccy, (1904), S. 108-109. Diese These wurde jedoch vom Historiker Roman Żelewski widerlegt. Nach dessen Erkenntnis wechselte das Gebetshaus der Arianer während seiner Existenz nie die Lage: Żelewski, Akta i relacje, S. 111. 
abgelehnt und nicht für christlich gehalten ${ }^{21}$. Deshalb wurden sie vom Consensus von Sandomir im Jahre 1570 ausgeschlossen, obwohl sie in Polen-Litauen schon relativ zahlreich vertreten waren ${ }^{22}$. Folglich waren sie in Krakau der siebziger Jahre des 16. Jahrhunderts einigermaßen geduldet. Der Hass der eifrigen Katholiken richtete sich nämlich in erster Reihe gegen diejenigen Protestanten, die in Bünden selbstbewusst und provozierend auftraten, was bei den Antitrinitariern nicht der Fall war.

\section{TUMULTE IM INTERREGNUM NACH DER FLUCHT HEINRICHS VON VALOIS}

Nach dem Tod des letzten Königs aus dem Jagiellonen-Geschlecht fürchtete man in Polen-Litauen, dass der langandauernde Machtkampf zwischen Katholiken und Protestanten und die daraus entstehenden Scharmützel zu einem desaströsen religiösen Bürgerkrieg führen könnten. Um dies zu vermeiden, wurde am 28. Januar 1573 die Warschauer Konföderation verabschiedet ${ }^{23}$. Sie funktionierte während des ersten Interregnums und während der kurzen Regierung Heinrichs von Valois. Als jedoch der junge König Polen-Litauens in der Nacht auf den 19. Juni

21 Die Abneigung der anderen protestantischen Konfessionen gegen sie drückte unter anderem Wojciech Węgierski aus: Kronika zboru ewangelickiego krakowskiego, S. 59. Ausführlicher zur Verbreitung und Lehre der Polnischen Brüder: Tazbir, Dzieje polskiej tolerancji, S. 66-69. Weiter auch ders., Arianie i katolicy, (1971); Z. Gołaszewski, Bracia polscy, (2005).

22 M. G. Müller, Der Consensus Sendomirensis - Geschichte eines Scheiterns? Zur Diskussion über Protestantismus und protestantische Konfessionalisierung in PolenLitauen im 16. Jahrhundert, in: Konfessionelle Pluralität als Herausforderung. Koexistenz und Konflikt in Spätmittelalter und Früher Neuzeit, hg. v. J. Bahlcke (u. a.), (2006), S. 397-408; Schramm, Der polnische Adel, S. 46-49.

23 Konfederacja warszawska 1573 roku, wielka karta polskiej tolerancji, hg. v. M. Korolko, J. Tazbir, (1980). G. Schramm, Ein Meilenstein der Glaubensfreiheit. Der Stand der Forschung über Ursprung und Schicksal der Warschauer Konföderation von 1573, „Zeitschrift für Ostforschung“, 24 (1975), S. 711-736. 
das Land hastig verließ, um die französische Krone nach dem Tod seines Bruders zu erlangen, wurde die Situation äußerst gespannt ${ }^{24}$.

Unter dem Adel herrschte Enttäuschung und Unsicherheit darüber, ob und wann ein neuer König gewählt werden sollte. Auf der einen Seite wollten viele noch abwarten, was man mit Heinrich von Valois in Frankreich vereinbart hatte, auf der anderen Seite gab es schon Überlegungen, welche die potenziellen Kandidaten für eine neue Wahl wären. Die habsburgische Partei schien stark an Einfluss zu gewinnen. Die Protestanten dagegen waren gespalten. Besonders gegen die Fraktion der Brüder Zborowski wurden viele Vorwürfe erhoben, weil sie sich vor anderthalb Jahren sehr für die Wahl Heinrichs von Valois eingesetzt hatten ${ }^{25}$. Dabei triumphierten sie nicht nur über die Anhänger der Habsburger, sondern auch über eine andere Fraktion des reformierten Adels, die einen protestantischen Kandidaten empfohlen hatte ${ }^{26}$. Als nun am 23. Juni 1574 der Wojewode von Krakau, Piotr Zborowski, an einem Treffen einiger einflussreicher Magnaten und Bischöfe teilnahm, versuchte der ebenfalls kalvinistische Wojewode von Podolien, Mikolaj Mielecki, ihn zu verprügeln ${ }^{27}$.

Die Uneinigkeit der Protestanten und die heftige Kritik, der etliche von ihnen ausgesetzt waren, nutzten ihre katholischen Gegner aus. Am 10. Oktober 1574 fand der erste große Angriff auf das protestantische Gebetshaus Bróg statt. Der Tumult wurde von dem Studenten der

24 K. Pražáková, T. Sterneck, „Rychlejší než větry, hbitější než všichni zajíci”. Utěk Jindřicha $z$ Valois $z$ Polska v pamfletu $z$ roku 1574, „Slovanský přehled“, 100, 3 (2014), S. 473-497.

25 M. Serwański, Henryk III Walezy. Stosunki polsko-francuskie w latách 1566-1576, (1976), S. 52-54; K. Pražáková, Obraz Polsko-litevského státu a Ruska ve zpravodajství české šlechty (1450-1618), (2015), S. 119, 159-160.

26 Schramm, Der polnische Adel, S. 53-54 und 259-261.

27 Státní oblastní archiv v Třeboň (Staatliches Gebietsarchiv Třeboň (deutsch Wittingau), weiter SOA Třeboň), Historica Třeboň, Sign. 4834/33: Handgeschriebene Zeitung vom 18.-23. Juni 1574. Zur Persönlichkeit von Mikołaj Mielecki, der später zum Großhetman der polnischen Krone wurde, R. Przybyliński, Hetman wielki koronny Mikołaj Mielecki (ok. 1540-1585), (2002). 
Krakauer Akademie, Hieronim Orzechowski, ausgelöst, der an einer Hochzeit in Bróg teilnahm und angeblich wegen der Auslassung des Namens der Jungfrau Maria in Gebeten empört war ${ }^{28}$. Deshalb soll er unverzüglich seine Freunde versammelt und zwei Tage lang das protestantische Gotteshaus geplündert haben ${ }^{29}$.

Der Verlauf der Attacke wies dabei etliche Merkmale auf, die auch für andere katholische Tumulte typisch wurden. Zum allerersten zielte der Tumult direkt auf das Zentrum des Protestantismus in der Stadt und zerstörte es in einem solchen Ausmaß, dass seine Benutzung für eine lange Zeit fast unmöglich war. So etwas konnte man mit Rechtsmitteln nicht erreichen. Ein weiteres wichtiges Merkmal besteht darin, dass die tatsächlichen Anstifter des Tumults unbekannt und folglich auch unbestraft blieben. Schon die Zeitgenossen bezweifelten, die Idee sei im Kopf eines Studenten entstanden ${ }^{30}$. Sie verdächtigten daher eher den Primas und Bischof von Gnesen Jakub Uchański, den päpstlichen Nuntius Vincentius Laureo oder den Rektor der Krakauer Akademie Marcin Glicjusz ${ }^{31}$.

Die Studenten der Krakauer Akademie scheinen in fast alle Tumulten verwickelt gewesen zu sein. Zusammen mit kleineren Handwerkern

28 Die Beschreibung des Tumults von Marcin Fox, dem Professor der Krakauer Akademie: „Die 10 mensis huius [X 1574] in synagoga haereticorum Cracoviae puer Orzechowski spectans matrimonium nominavit Beatam Virginem Mariam, cui eam ob rem colophum dedit. [...] Duravit tumultus iste ad diem martis“. Materiały do dziejów reformacji, Nr. 21, S. 20.

29 Eine gewisse Erklärung, warum die Plünderung so lange dauern konnte, lieferte der protestantische Chronist Wojciech Węgierski: „Z zamku też pan Stanisław Palczewski, podstarości krakowski, ewangelik, z piechotą zamkową przyść i przybyć nie śmiał, obawiając śię jakiey zdrady, aby się pod czas interregnum, do zamku hultajstwo nie werwało.[...]“: Kronika zboru ewangelickiego krakowskiego, S. 71.

30 Żelewski, Akta i relacje, S. 114-115.

31 Marcin Glicjusz sprach über das protestantische Gebetshaus mit Verachtung, die auch in seinem Diarium zum Ausdruck kommt: „10 octobris 1574 usque ad 12 conciliabulum haereticorum, Bróg appellatum, Cracoviae oppugnatum et direptum“. Materiały do dziejów reformacji, Nr. 20, S. 20. 
und ärmeren Leuten stellten sie die Mehrheit und die treibende Kraft der Masse dar, die von katholischer Seite die Unruhen anstifteten und durchführten ${ }^{32}$. Wenn es aber zu Verurteilungen kam, entgingen die Studenten meist der Bestrafung ${ }^{33}$. So schon nach der Plünderung von Bróg im Oktober 1574. Fünf Teilnehmer des Tumults, die der Krakauer Wojewode Piotr Zborowski am 26. Oktober 1574 wegen Plünderung, Diebstahl und Verpfändung der gestohlenen Güter hinrichten ließ, gehörten zu den niederen Gesellschaftsschichten ${ }^{34}$.

Das Materielle spielte von Anfang an eine große Rolle. Die Möglichkeit, sich bei der Plünderung zu bereichern, war für viele Stadtbewohner offenbar ein wichtiger Beweggrund für die Teilnahme. Gerade beim ersten Übergriff auf das protestantische Gebetshaus war die Beute sehr groß. Die Zeitgenossen sprachen von über mehrere tausend Gulden, die dort einige Protestanten aufbewahrt hatten ${ }^{35}$. Eine solche Beute allein konnte schon zur Wiederholung der Tumulte beitragen. Die Beute war jedoch nie wieder so groß, denn die Protestanten lagerten nach dem Jahr 1574 nicht mehr so viele Wertsachen in Bróg.

Obwohl die persönliche Bereicherung eine große Rolle spielte, war der Tumult von feierlichen Glaubensäußerungen begleitet. Beim Heraustragen der protestantischen Gesang- und Gebetsbücher sang man zum Beispiel den Lobgesang Te deum laudamus. Diese Tatsache

32 Die Situation der Krakauer Akademie beschreibt ein älteres, jedoch immer noch nützliches Werk: H. Barycz, Historia Uniwersytetu Jagiellońskiego w epoce humanizmu, (1935). Weiter auch I. Kaniewska, R. Żelewski, W. Urban, Studia z dziejów młodzieży Uniwersytetu Krakowskiego w dobie Renesansu, (1964).

33 Die Vorschläge, auf welche Art und Weise die Studenten bestraft und die ganze Akademie kontrolliert werden soll, sind im Brief des protestantischen Adels aus Kleinpolen zu finden, in: Materiały do dziejów reformacji, Nr. 45, S. 35-39.

34 Das Rathausprotokoll vom 26. Oktober 1574, der die Aussagen und Strafen der fünf Bestraften zusammenfasst in: Materiały do dziejów reformacji, Nr. 47, S. 40.

35 In der Klage behauptete der Gemeindeälteste Stanisław Karniński Iwan, dass aus dem Gebetshaus unter anderem 40.000 Gulden entwendet wurden, die dem Böhmischen Bruder Rafał Leszcyński gehörten. Materiały do dziejów reformacji, Nr. 27, S. 24-25. 
verärgerte die Protestanten erheblich, die den Vorfall vor allem als Angriff auf ihre Rechte und den Besitz ihrer Gemeinde verurteilt wissen wollten ${ }^{36}$.

In der Zeit des Interregnums, nach der Flucht Heinrichs von Valois, kam es noch zu zwei weiteren Unruhen, die von Studenten der Krakauer Akademie provoziert wurden und unter anderem wegen des Zeitpunktes interessant sind. Beim ersten blieb es aber bei dem Versuch. Am 12. Mai 1575 versuchten unbekannte Studenten in das wieder in Stand gesetzte Gebetshaus Bróg einzudringen. Sie wurden jedoch zurückgeschlagen ${ }^{37}$. Das Datum dieser Aggression war überlegt gewählt. Am 12. Mai 1575 feierte man Christi Himmelfahrt. Zugleich lief der späteste Termin ab, an dem Heinrich von Valois als polnischer König zurückkehren konnte. So begann am 12. Mai 1575 ein Interregnum, in dem der König durch einen königlichen Verwalter mit beschränkter Macht ersetzt wurde ${ }^{38}$. Zu diesem interimistischen König wurde ebenso wie im Jahre 1572 der Primas von Polen Jakub Uchański, der zu den Anhängern der katholischen Habsburger gehörte, gewählt ${ }^{39}$. In einer solchen Situation war eine Bestrafung der Aggressoren erschwert ${ }^{40}$. Darüber hinaus konnte eine Ausplünderung des protestantischen

36 „...Te Deum laudamus śpiewali, Contere, domine, inimicos nostros i ognie triumpharum ex victoria palili“: Die Klage der kleinpolnischen Adeligen vom 25. Oktober 1574 in Materiały do dziejów reformacji, Nr. 45, S. 35-39, hier S. 37.

37 Świętosława Orzelskiego Bezkrólewia ksiąg ośmioro 1572-1576, hg. v. E. Kuntze, (Scriptores rerum Polonicarum 22, 1917), S. 315.

38 J. Dzięgielewski, Prymasi $w$ roli interreksów, in: Prymasi i prymasostwo $w$ dziejach państwa i narodu polskiego, hg. v. W. J. Wysocki, (2002), S. 39-50.

39 Ch. Augustynowicz, Die Kandidaten und Interessen des Hauses Habsburg in Polen-Litauen während des zweiten Interregnums 1574-1576, (2001), S. 130-132.

40 Jakub Uchański hatte gute Kontakte auch zu Protestanten und kann nicht einfach als Befürworter einer gewaltsamen Gegenreformation gelten. Dennoch konnten sich die Provokateure eines Tumults sicherer fühlen, wenn der interimistische König ein katholischer Bischof war. R. Po-chia Hsia, The World of Catholic Renewal 1540-1770, (1999), S. 62. 
Gebetshauses im Zentrum von Krakau schon die aktuellen Machtverhältnisse wie die bevorstehende Königswahl beeinflussen.

Der andere Tumult fand am 24. Juni 1575 statt. Seine Anstifter nutzten das Fest des heiligen Johannes des Täufers aus und hetzten einen Teil der Versammelten gegen die Protestanten auf. Diesmal griffen sie den protestantischen Friedhof hinter dem Nikolaustor $\mathrm{an}^{41}$. Es bleibt eine offene Frage, ob sie ursprünglich das Gebetshaus Bróg angreifen wollten und wegen bewaffneter Wachen davon zurückwichen ${ }^{42}$, oder ob der Friedhof von Anfang an als Angriffsziel bestimmt worden war, was eigentlich besser zur geheimnisvollen Atmosphäre des christlichheidnischen Festes des heiligen Johannes gepasst hätte ${ }^{43}$. Jedenfalls zerstörten die Studenten und Menschen aus niederen Volksschichten in der Nacht nicht nur Grabsteine, sondern schändeten auch die Leichen. Sie holten sie aus dem Grab und verspotteten sogar den Leichnam des ehemaligen Krakauer Wojewoden Stanisław Myszkowski, der im Jahre 1570 gestorben war und dessen Brüder 1557 zwei katholische Geistliche verprügelt hatten ${ }^{44}$. Die Verwüstung des Friedhofs inklusive der Schändung der Leichen im Juni 1575 stellte einen skrupellosen Angriff auf die sakral-memoriale Sphäre des Feindes (der Protestanten) dar.

41 Der Briefwechsel der Schweizer mit den Polen, hg. v. T. Wotschke, (Archiv für Reformationsgeschichte Ergänzungsband 3, 1908), S. 379.

42 Andeutungen in: Materiały do dziejów reformacji, Nr. 86 u. 87, S. 71-72.

43 Auf einen gewissen Zusammenhang mit heidnischen Gebräuchen machte schon der protestantische Chronist Wojciech Węgierski aufmerksam: „[...]inszych zacnych ludzi ciała z grobów wywłóczyli, nogami wzgóre stawiali, rozlicznie lżyli i stromoczyli, okopy ogrodowe porozwalali i insze insolencje neizbożne a prawie pogańskie czynili“ s. Kronika zboru ewangelickiego krakowskiego, S. 76.

44 Zur Bedeutung von Stanisław Myszkowski für die Reformation in Polen: Schramm, Der polnische Adel, S. 50-51 


\section{VERURTEILUNG DER UNRUHESTIFTER UNTER STEPHAN BÁTHORY}

Die religiös motivierten Unruhen endeten nicht gleich nach der Königswahl von Stephan Báthory. Katholiken wie Protestanten nutzten bis zum Anfang des Jahres 1578 die Lage aus, als der König die revoltierende Stadt Danzig belagerte und daher seine Macht im Königreich Polen nicht voll ausüben konnte ${ }^{45}$. Zu den aktivsten Provokateuren unter den Protestanten gehörten die Adeligen Piotr Tomicki und Jan Stadnicki. In den Jahren 1576 und 1577 versuchten sie mehrmals, Studenten der Krakauer Akademie, Mönche oder Geistliche einzuschüchtern. Sie verprügelten ihre Gegner ${ }^{46}$. Nachts am 17. Februar 1577 öffneten sie das Stadttor in der Nähe der Krakauer Akademie. Ferner beschädigten sie am 24. Februar 1577 die Grabsteine auf dem St. Marienfriedhof ${ }^{47}$. Für ihre Aktionen wählten sie meist Sonntage vor Ostern.

Auch die Katholiken provozierten Unruhen vorwiegend in der Osterzeit, zu Christi Himmelfahrt und an Namenstagen von bekannten Heiligen. Die Rache für Jan Stadnickis und Piotr Tomickis Aktionen folgte zum Beispiel während der Osteroktav am 11. April 1577. Eine Volksmenge, geführt von Studenten, attackierte das Gebetshaus Bróg, wobei der protestantische Prediger Daniel Bileński verletzt wurde ${ }^{48}$. Stephan Báthory, der sich in Warschau aufhielt, reagierte mit zwei

45 J. Besala, Stefan Batory, (1992), S. 180-224; K. Lepszy, Stefan Batory a Gdańsk, „Rocznik Gdański“, 4 (1932), S. 2-56.

46 Jan Stadnicki wollte sogar einem Mönch die Geschlechtsorgane abschneiden: „7 martii 1577 Stadnicki veniens in balneo ad Sanctum Franciscum reperit ibidem monachos ordinis praedicatorum er ampla novacula, voluit abscindere genitalia Sigismundo monacho, quod quidem fecisset, nisi germanus frater eiusdem Stadnicki precibus ipsum liberasset“. Die Edition der Notizen von Marcin Glicjusz: Materiały do dziejów reformacji, Nr. 96, S. 77-78.

47 Die Klagen über die Angriffe von Piotr Tomicki vom 27. Juni und 28. Juli 1576 in: ebenda, Nr. 89-95, S. 73-77. Über Jan Stadnicki: ebenda, Nr. 96, S. 77-78.

48 Der Protest des Predigers, in dem er am 18. März seine Verletzungen beschrieb, in: ebenda, Nr. 98, S. 78-79. 
Mandaten, die jedoch in seiner Abwesenheit nicht viel halfen ${ }^{49}$. Vor dem Fest von Johannes dem Täufer bereiteten sich die Protestanten auf den Schutz des Gebetshauses vor. Die Plünderung fand jedoch (wohl wegen der Nachrichten über die Verteidigungsmaßnahmen) schon am 21. Juni 1577 statt und betraf den Friedhof ${ }^{50}$. Die Tatsache, dass die Schuldigen nicht bestraft wurden und obendrein noch mit dem erbeuteten Schmuck der Verstorbenen entkamen ${ }^{51}$, führte dann am Fest der Mariae Heimsuchung am 2. Juli 1577 zur Plünderung von einigen Häusern der protestantischen Handwerker im Stadtteil Kleparz ${ }^{52}$. In diesen Ausschreitungen kamen nicht nur konfessionelle Spannungen zum Ausdruck, sondern auch Verdächtigungen gegen Deutschsprechende, denn ein beträchtlicher Anteil der Bewohner von Kleparz stammte aus verschiedenen Gebieten des Heiligen Römischen Reiches ${ }^{53}$.

Außer Tagen mit besonderer Stellung im Kirchenkalender nutzten die verfeindeten Konfessionen auch andere günstige Gelegenheiten aus. Als im März 1578 die Druckerei von Aleksy Rodecki ${ }^{54}$ brannte, behinderten katholische Studenten das Löschen. Die geretteten Bücher

49 Die Mandate vom 27. April 1577, in: ebenda, Nr. 99 u. 100, S. 79-80. Die Königsanordnungen verloren auch dadurch an Wirkung, weil der verhaftete Student, der den Prediger verletzt hatte, entflohen war: „26 maii 1577 Puhacz ex carceribus evolavit fuga, effractis foribus ferreis“. Die Notiz aus dem Diarium von Marcin Glicjusz: ebenda, Nr. 105, S. 81.

50 Kronika zboru ewangelickiego krakowskiego, S. 77.

51 „[...]do grobu nieboszczyka pana Erazma Aichlera się dobili i w nim jednę trunnę szukając, jako jakiej zdobyczy dobywszy, połupali i potłukli“. Ebenda, S. 77.

52 Materiały do dziejów reformacji, Nr. 112-115, S. 84-86.

53 Mehr: Z dziejów Kleparza. W 600 rocznicę nadania praw miejskich przez Króla Kazimierza Wielkiego, (1968).

54 Über die Persönlichkeit und das Werk des Druckers Aleksy Rodecki: J. Pirożyński, Winkelzüge und Fälschungen in der Praxis der Krakauer Buchdrucker des 16. und 17. Jahrhunderts, in: Studien und Essays zur Druckgeschichte. Festschrift für Claus W. Gerhardt zum siebzigsten Geburtstag, hg. v. R. Münch, (1997), S. 89-97, hier S. 90-91; A. Kawecka-Gryczowa, Les imprimeurs des antitrinitaires polonais Rodecki et Sternacki. Histoire et bibliographie, (1974). 
warfen sie dann zurück ins Feuer ${ }^{55}$. Am 1. Juni 1578 vergriffen sich die Studenten wiederum bei der Begräbnisfeier einer Protestantin, deren Leichnam sie sogar in die Weichsel warfen ${ }^{56}$. Nach einem solchen „Erfolg“ versuchten sie gleich am nächsten Tag das Gebetshaus Bróg zu stürmen, aber sie wurden zurückgeschlagen ${ }^{57}$. Die Protestanten antworteten am 18. Juni 1578 mit der Störung eines Begräbnisses in der Franziskanerkirche sowie mit Angriffen auf Studenten der Krakauer Akademie, katholische Priester und in der ersten Septemberhälfte 1578 sogar auf den Nuntius Giovanni Andrea Caligieri ${ }^{58}$. Zugleich unterbreiteten beide Seiten seit Mitte 1577 ihre Beschwerden, Bitten und Vorschläge dem König. Die Katholiken bemühten sich dabei nicht nur um die Rechtfertigung studentischen Vorgehens ${ }^{59}$, sondern Kardinal Stanisław Hosius schlug dem König auch mehrmals die Verlagerung des protestantischen Gebetshauses aus der Krakauer Innenstadt vor ${ }^{60}$.

55 Die Beschreibung des Vorfalls im Brief von Stanisłaus Hosius vom 19. April 1578: Materiały do dziejów reformacji, Nr. 125, s. 96. Der Kommentar: J. Tazbir, Szlachta i teologowie. Studia $z$ dziejów polskiej kontrreformacji, (1987), S. 165.

56 „1 iunii 1578. Eodem die accidit tumultus magnus Cracoviae circa cadaver mulieris evangelicae, quod faex populi sepeliendo impedivit, direpto panno lugubri, profligato auriga cum equis, cadavere attrito lapidibus, baculis admodum, extractum in curru ex urbe sepelierunt in Istula“: Materiały do dziejów reformacji, Nr. 126, S. 97. Begräbnisse stellten einen wichtigen Anlass zur Demonstration von konfessionellen Forderungen und Feindseligkeiten dar. Ausführlich: C. Koslofsky, Honour and Violence in German Lutheran Funerals in the Confessional Age, „Social History“, 20 (1995), S. 315-337.

57 Materiały do dziejów reformacji, Nr. 127-132, S. 97-100.

58 Detaillierte Beschreibungen dieser Vorfälle in den Berichten des Nuntius in: $I$. A. Caligarii nuntii apostolici in Polonia epistolae et acta 1578-1581, hg. v. L. Boratyński, (1915), S. 52-53. Weitere Dokumente: Materiały do dziejów reformacji, Nr. 145-147, S. 109-111.

59 Bemerkenswert ist besonders der Brief von Piotr Myszkowski vom Anfang April 1578, in dem der Krakauer Bischof versuchte, die Schuld an den Unruhen nicht den Studenten, sondern den armen Leute zu geben: Materiały do dziejów reformacji, Nr. 128, S. 97-98.

60 Zwei Briefe von Stanislaw Hosius an den König vom 24. Oktober 1578 in: 
Darauf ging Stefan Báthory jedoch nicht ein ${ }^{61}$. Um den Religionsfrieden zu bewahren, erließ er am 27. Oktober 1578 ein Mandat, in dem er allen Teilnehmern der Tumulte ohne Rücksicht auf ihre Herkunft und soziale Stellung die Todesstrafe androhte ${ }^{62}$. Wie mit den Tätern verfahren werden sollte, konnte weiterhin nur ein Königsgericht entscheiden. Außerdem kam es zur Regelung der Studentenunterkünfte, des Besitzes von Schusswaffen sowie zur Verstärkung von Nachtwachen ${ }^{63}$.

Das energische Vorgehen von Stefan Báthory sorgte für das Abklingen religiös motivierter Unruhen. Nur ausnahmsweise, meist wenn der König auf einem Kriegszug weilte, kam es zu kleineren Scharmützeln. Am 22. April 1580 beschädigten zum Beispiel die Katholiken die Mauer des protestantischen Friedhofs ${ }^{64}$. Viele Streitigkeiten begleiteten auch das Begräbnis des Krakauer Wojewoden Piotr Zborowski am 19. Januar 1581, des einflussreichen Förderers der Protestanten ${ }^{65}$. Von protestanti-

ebenda, Nr. 118-119, S. 87-91. Ein weiterer Brief verfasste dann Stanislaw Hosius am 28. Oktober 1578: ebenda, Nr. 142, S. 107-108.

61 Der Brief des Königs an Kardinal Stanisław Hosius vom 4. Februar 1579: ebenda, Nr. 120, S. 92-93.

62 „Imprimis statuimus et edicimus Nequisquam hominum cuiuscunque illefuerit locidignitatis; Conditions atque professionis, tam externus quam Indigena, audeat in Civitate eadem, tumultus aut urbas aliquas excitare vel seditiones facere quacunque ex causa, Sive privatae sive publicae rei, sive Religionis etiam gratia. Domos item quaecunque Civitatis et oppidorum illi adiunctorum et Suburbiorun ambitu continentur cuiuscunque illae fuerint et quibuscunque Usibus destinatae, ne quisquam pervim aggrediatur et invadat, vel armis aut Lapidum jactu pugnet vel impetum aliquem in eas faciat; Sub poena Capitis in eum, qui Legitime hoc Nomine convictus fuerit, extendenda": Mandat des Königs Stefan Bátory für die Erhaltung des Friedens in Krakau vom 27. Oktober 1578, in: Kronika zboru ewangelickiego krakowskiego, S. 78-85, hier 80.

63 Ebenda, S 80-81.

64 Materialy do dziejów reformacji, Nr.160, S. 120.

65 Ebenda, Nr. 164-166, S. 122-123. Die freigiebige finanzielle Unterstützung, die Piotr Zborowski dem Krakauer Gebetshaus gewährte, belegen die Angaben über Jahressammlungen in: Kronika zboru ewangelickiego krakowskiego, S. 74-75. Zur Persönlichkeit von Piotr Zborowski ausführlicher: Schramm, Der polnische Adel, S. 51, 96-97. 
scher Seite her belästigte man meist die Studenten der Krakauer Akademie. An der Wende vom Januar zum Februar 1581 sorgte Jan Stadnicki für einigen Verdruss. Bei einer seiner Ausschreitungen wurde am 1. Februar 1581 sogar der Bakkalaureus Wawrzyniec Gadomski getötet ${ }^{66}$. Ein anderer Student der Krakauer Akademie, Wojciech Wojas, wurde wiederum am 15. August 1582 getötet, als die betrunkenen Diener des adeligen Kalvinisten Mikołaj Dłuski das Studentenwohnheim beschos$\operatorname{sen}^{67}$. Im Allgemeinen, so behauptete jedoch Wojciech Węgierski, „gab es Frieden, solange dieser König lebte und Gebete konnten in protestantischen Kirchen ruhig verrichtet werden" 68 .

Obwohl Stephan Báthory von diesem protestantischen Chronisten und Prediger so gelobt wurde, war er kein Förderer der Reformation. Er beschützte die protestantischen Gemeinden im Rahmen seiner vernünftigen Politik, zugleich bemühte er sich allerdings um einen allmählichen und friedlichen Sieg des Katholizismus, in dem er eine das Königreich einigende Kraft sah. In manche Königsstädte lud er Jesuiten ein und gewährte ihnen gute Bedingungen ${ }^{69}$. In Krakau bekamen die Jesuiten zum Beispiel die Kirche St. Barbara, die zwar relativ klein war, jedoch direkt am Hauptplatz neben der Marienkirche lag. Gute Standorte von Jesuitenkirchen und -kollegien gaben den Ordensmitgliedern viele Möglichkeiten, auf die Stadtbevölkerung einzuwirken.

Viele Erfolge erzielten sie mit ihren Schulen, Predigten, Beichten, Theateraufführungen und Bruderschaften. Alle diese Aktivitäten konn-

66 Materialy do dziejów reformacji, Nr. 167-172, S. 124-128.

67 Ausführliche Beschreibungen des ganzen Vorfalls: Materiaty do dziejów reformacji, Nr. 175-176, S. 130-132.

68 „[...]przez kilka lat, póki ś. p. król Stefan żył, był jaki taki pokój i nabożeństwa we zborze krakowskim spokojne odprawowanie [...]“": Kronika zboru ewangelickiego krakowskiego, S. 85.

69 Ausführlicher in einem älteren, jedoch viele Informationen beinhaltendem Werk: S. Załęski, Jezuici w Polsce, 1: Walka z różnowierstwem 1555-1608, (1906), S. 242-260. Weiter auch: S. Obirek, Działalność kulturalna jezuitów w Rzeczypospolitej Obojga Narodów (1564-1668). Próba syntezy, (1996). 
ten den Protestantismus nicht nur auf eine friedliche Art und Weise bekämpfen, sondern führten gelegentlich zu Tumulten. Die Studenten aus den jesuitischen Schulen wurden bald zu einer weiteren Gruppe, die sich gerne in religiös motivierte Unruhen einmischte, besonders wenn sie ihre Ursachen in einem passenden Theaterstück oder einer Predigt hatten ${ }^{70}$. An Bedeutung gewannen auch die Bruderschaften, deren Wirkungssphären in Ostmitteleuropa noch nicht ausreichend erforscht sind. Dennoch lässt sich schon anhand der bisherigen Kenntnisse erkennen, dass sie bei der Mobilisation der katholischen Kräfte eine wichtige Rolle spielten, indem sie Gruppen von ähnlich gesinnten und sich gegenseitig fördernden Personen bildeten.

\section{DIE ZERSTÖRUNG VON PROTESTANTISCHEN GOTTESHÄUSERN IM SCHLÜSSELJAHR 1591}

Die Tatsache, dass während der letzten zehn Jahre die Katholiken an Einfluss gewannen und manche von ihnen Auseinandersetzungen suchten, wurde bald nach dem Tode von Stephan Báthory offenbar. Am 7. Mai 1587 wurde das Fest Christi Himmelfahrt in der Marienkirche auf dem Krakauer Hauptplatz gefeiert. Nach der Abschlusspredigt zog eine Volksmenge zum Gebetshaus Bróg, wobei sie eine Teufelsfigur mitschleppte, die zuvor bei dem feierlichen Gottesdienst benutzt worden war $^{71}$. Die Provokation ging allmählich in ein bewaffnetes Schar-

70 Zur Rolle von Predigten in der Reformation sowie Gegenreformation: Tazbir, Szlachta, S. 95-109. Zu den Konflikten in Wilna, das auch ein jesuitisches Zentrum war, s.: T. Kempa, Konflikty wyznaniowe w Wilnie od początki reformacji do końca XVII wiek, (2016).

71 „Die solemni Calixti in caelum abeuntis nobis pro Regni necessitatibus in templo nostro supplicacionem producentibus, pueri scholares vetere ludiero larvam diaboli e turre praecipitarunt et quaerentibus quorsum illam diaboli larvam inquam eicerent, exclamat aliquis: ad Synagogam“: Ks. Jana Wielewickiego S. J. Dziennik spraw domu zakonnego OO. Jezuitów u ś. Barbary w Krakowie od r. 1579 do r. 1599 (włącznie), hg. v. J. Szujskij, (1881), S. 101. 
mützel über. Am Abend waren die katholischen Angreifer so zahlreich und gut ausgerüstet, dass es ihnen gelang, in Brog einzudringen und in einem Ausmaße zu plündern, dass angeblich nur die Umfassungsmauern übrigblieben ${ }^{72}$. Bei diesem Vorfall nutzten die Rädelsführer nicht nur den Festtag und die Abwesenheit des Königs, sondern auch die Tatsache aus, dass die einflussreichen Persönlichkeiten, einschließlich des Krakauer Starosten Mikołaj Zebrzydowski, in Proszowice, ca. 30 $\mathrm{km}$ weit von Krakau, versammelt waren ${ }^{73}$. Neu war die Beteiligung von jesuitischen Schülern und Studenten, die nach einigen Dokumenten in größerem Umfange als die Studenten der alten Akademie angeklagt wurden ${ }^{74}$.

Nach Rückkehr der Stadtoberen stellte man Ermittlungen an und einige der Täter wurden eingekerkert ${ }^{75}$. Obwohl die Strafen den Protestanten als zu mild erschienen ${ }^{76}$, trugen sie zur Beruhigung der Situation viel bei. Von Sommer 1587 bis Mai 1591 schreckte man offensichtlich davor zurück, gegen religiöse Opponenten gewaltsam vorzugehen. Ein einziger bekannter Fall stellt die Zerstörung des Gebetshauses der Polnischen Brüder dar. Neu ist die Art der Vorgehensweise, denn die

72 Materiały do dziejów reformacji, Nr. 182-2015, S. 138-159.

73 „Pod ten czas bowiem, zaraz nazajutrz po Niebowstaniu Pańskim, przypadała lustratio nobilitatis albo okazowanie szlachty pod Proszowicami; na które, gdy jmp. Mikołaj Zebrzydowski, starosta krakowski, także jmp. Stanisław Cikowski, podkomorzy krakowski, na ten czas w niebytności, wojewody krakowskiego vicetenens województwa krakowskiego ze wszystką piechotą, która miał przy Krakowie, do Proszowic odjechali, [...]“: Kronika zboru ewangelickiego krakowskiego, S. 89.

74 Materiały do dziejów reformacji, Nr. 187, S. 141. Mehr dazu: H. Barycz, Geneza $i$ autorstwo "Equitis poloni in iesuitas actio prima" (studjów nad polemiką antyjezuicka w Polsce część 1), (1934), S. 65-68.

75 Kronika zboru ewangelickiego krakowskiego, S. 90-91.

76 „[...]z których jednych mniej winnych uwolniono drugich na rękojemstwo wypuszczono, trzecich do więzienia dano [...] Ta sprawa jakoby się potym toczyła, wiadomości nie masz: to tyłko pewną, że po długich prawnych terminach, które się przez dwie lecie z kosztem niemałym wlokły, żadna się nie stała słuszna sprawiedliwości [...]": Kronika zboru ewangelickiego krakowskiego, S. 91. 
Kirche wurde nicht von einer bestimmten katholischen Gruppe angegriffen, sondern in der Nacht auf den 26. Juni 1588 von unbekannten Tätern in Brand gesteckt ${ }^{77}$. Der Stadtrat versuchte diesen Fall zu klären, indem er einige Bettler verhaften ließ, aber dies brachte kein Ergebnis. Die Folterung der Verdächtigen konnte jedoch wieder als Abschreckung und Warnung wirken ${ }^{78}$.

Die protestantische Kirche Bróg sowie das Gebetshaus der Polnischen Brüder wurden an der Wende der achtziger und neunziger Jahre des 16. Jahrhunderts mit der Erlaubnis von Sigismund III. Wasa wieder renoviert ${ }^{79}$. Dennoch wurde am Anfang der neunziger Jahre den Eliten als auch den weniger einflussreichen Personen klar, dass der neue König einen stark katholischen Kurs verfolgte, den Jesuiten jetzt viel Gehör schenkte ${ }^{80}$ und bei der Verteilung der Ämter Katholiken bevorzugte, wenn es in der gegebenen Situation möglich war ${ }^{81}$. Hinzu trat ein Generationswechsel bei einigen mächtigen

77 Beschreibungen des Vorfalls aus verschiedenen Positionen in: Materiały do dziejów reformacji, Nr. 217-222 u. 226-227, S. 164-166 u. 169.

78 In den Stadtrechnungen vom Juli 1588 verrechnete man Kerzen, Seile und Ruten, die bei der Folterung von Verdächtigen benutzt wurden: ebenda, Nr. 223, S. 167.

79 Zum Jahre 1590 notiert ein unbekannter Bürger in seiner Chronik: „W tymże roku zbór na ż. Jana ulicy w krakowie całe lato budowano, prawie od gruntu aże do wirzchu, po wypaleniu a zepsowaniu wtórem: sklep o swu filarach zasklepiono dla polskiego kazanią, a na wierzchu dla Niemców zostawiono“: Kronika mieszczanina krakowskiego z lat 1575-1595, hg. v. H. Barycz, (1930), S. 85.

80 S. Obirek, Jezuici na dworach Batorego i Wazów 1580-1668. Wpływ kapelanów dworskich i wychowawców książą na postawy panujących i politykę państwa, (1996), S. 219-312; W. Leitsch, Das Leben am Hof König Sigismunds III. von Polen, 2. Bd. (2009), S. 866-896; Tazbir, Piotr Skarga, S. 120-124.

81 H. Wisner, Zygmunt III. Waza, (1991), S. 56-58. Die einseitige Erteilung von Ämtern an Katholiken bestritt teilweise Walter Leitsch, aber die Quellen zeigen, dass der König eine Gruppe seiner Treuen bilden und belohnen wollte: Leitsch, Das Leben am Hof, S. 727-740. Ein anderes wichtiges Werk J. Dzięgielewski, Jak i dlaczego powstat wizerunek Zygmunta III Wazy jako władcy nietolerancyjnego?, „Miscellanea HistoricoArchivistica“, 23 (2016), S. 153-161. 
protestantischen Adelsfamilien ein, der in einigen Fällen zu einem Konfessionsübertritt führte ${ }^{82}$.

Es ist nicht völlig klar, nach welchen Indizien die Krakauer Katholiken im Frühling 1591 glaubten, sie könnten nun die protestantischen Kirchen zerstören, ohne dafür schwer bestraft zu werden. Jedenfalls begingen sie am 23. Mai 1591 eine sehr gewagte Aktion, denn sie griffen das protestantische Gebetshaus an, während der König auf dem Schloss Wawel gleich oberhalb der Stadt weilte ${ }^{83}$. Anlässlich des Festes Christi Himmelfahrt wiederholten sie den Vorstoß vom 7. Mai 1587. Wie vor vier Jahren fing der Angriff in der Marienkirche auf dem Hauptplatz an, in der während des Gottesdienstes ein Christusbildnis feierlich nach oben zur Wölbung gezogen wurde, während eine Teufelspuppe vom Turm hinunter gestürzt wurde ${ }^{84}$. Die Menschenmenge, deren Führung Studenten und Sprecher der ärmeren Volksschichten übernahmen, schleppte diese Figur nach Bróg 85 .

82 Schramm, Der polnische Adel, S. 36 u. 57-58.

83 Materiały do dziejów reformacji, Nr. 229-255, S. 170-187. Auch ein Bericht darüber in: SOA Třeboň, Historica Třeboň, Sign. 5548/B. Ausführliche Analyse: K. Pražáková, Konfesní nepokoje v Krakově pohledem rožmberského zpravodajství,„Folia historica Bohemica“, 30, 1 (2015), S. 5-32.

84 „Also haben sie auch in diesem Jahr [...] die Baepstischen zu Cracaw ihren Herr Gott in der grossen Kirchen auff dem Marckt, ihrem brauch nach, gehn Himmel geschickt und hergegen ein hoeltzern Monsturm, den Teuffel bedeutendt, herab gelassen", die chronikalische Schilderung von Conrad Memmius, der den Pseudonym Jacob Francken benutzte, in: Jacobi Franci Relatio historica quinquennalis. Wahrhaffige Beschriebung aller fürnemmen unnd gedenckwürdigen Geschicht, so sich innerhalb funff Jahren, nemlich, vom Anno 1590 biß 1595 zugetragen haben, (1595), S. 52 (URL: http://daten.digitale-sammlungen.de/ db/0002/bsb00024843/images/, aufgerufen 16.06.2017).

85 Der jesuitische Prediger Piotr Skarga behauptete später, dass die Aufstellung der Teufelsfigur vor dem protestantischen Gebetshaus schon eine gewisse Tradition hatte: P. Skarga, Upominanie do ewángelikow y inych niekátholikow, $z$ strony zboru Krákowskiego, zburzonego roku Pánsk. 1591, in: ders., Kazania o siedmi Sakramentach, (1600), S. 444 (URL: http://www.dbc.wroc.pl/dlibra/docmetadata?id=2281\&from=pu blication, aufgerufen 26.11.2016). 
Sie konnten jedoch nicht einfach eindringen, denn nach vorigen Erfahrungen waren Fenster und Türe mit eisernen Gittern versehen. Die Protestanten gewannen daher Zeit, in der ein Mitglied des Stadtrates zum König auf die Burg eilte. Sigismund III. bezweifelte jedoch zuerst den Ernst der Lage, und wollte nichts unternehmen. Eine Zeit lang verteidigten also nur etliche bewaffnete Diener einiger protestantischer Adeliger die Kirche Bróg. Dann schickte allerdings der König seine Heiducken und beendete den Streit.

In der Nacht versammelten sich die Studenten und Menschen aus niedrigeren Volksschichten wieder und plünderten und verbrannten nicht nur Bróg, sondern auch die arianische Kirche ${ }^{86}$. Da sie offensichtlich nicht bestraft wurden, rotteten sie sich in der Nacht auf den 25. Mai wieder zusammen und fingen an, auf dem protestantischen Friedhof die Leichen aus den Gräbern herauszuzerren und in die Weichsel zu werfen. Diesmal griff jedoch der König scharf ein. Seine Heiducken töteten etwa 50 Aufrührer und weitere 30 brachten sie ins Gefängnis $^{87}$.

Aus den Reaktionen des Königs wurde klar, dass er auf jeden Fall den Friedhof unangetastet lassen wollte. Er respektierte ihn als eine memorial-sakrale Sphäre und wollte nicht in Konflikt mit den Familien geraten, deren Mitglieder dort begraben waren. Auf der anderen Seite war Sigismund III. offensichtlich unschlüssig, in wie weit er die protestantischen Kirchen beschützen sollte ${ }^{88}$. Ihre Lage im Stadtzentrum

86 „desgleich[en] laufen sie der Arÿaner Haus zue, zerschlagens, und plünd[er]ns von oben bis zue underst [...]“: SOA Třeboň, Historica Třeboň, Sign. 5548/B.

87 Jacobi Franci Relatio historica, S. 54. Ebenso: SOA Třeboň, Historica Třeboň, Sign. 5548/B.

88 Die Passivität Sigismunds III. Wasa bezüglich der Verteidigung von Bróg ärgerte die Protestanten in dem Maße, dass sie dem König Gefallen an der Zerstörung vorwarfen: „[...] trzecie walne, a ostatnie tegoż zboru zburzenie nastąpiło w przytomności samego króla, ś. p. Zygmunta trzeciego; gdzie podobnymże sposobem jako i przedtym, studenci swawolni i hultajstwo na zbór napadszy, nie tylko wszystko wyłupili i wybrali, ale oraz ogniem cale znieśli, tak że same tylko mury zostały, na który ogień jako twierdzili niektórzy, sam król JM zapatrować się miał", in: Kronika zboru ewangelickiego 
störte unter anderem seine Berater aus der Gesellschaft Jesu, die ihn in derselben Zeit für den Bau einer größeren Kirche im Stadtzentrum gewinnen wollten und einen Platz dafür suchten. Im Jahre 1597 wurde für sie die St. Peter-und-Paul-Kirche gegründet, die auf der Verbindungslinie zwischen dem Hauptplatz und dem Stadtteil Kazimierz liegt. Im Jahre 1591 zeichnete sich allerdings diese Gründung noch nicht klar ab und es gab Gerüchte, dass die Jesuiten das Stadtvolk auch deswegen gegen protestantische Kirchen aufhetzten, weil sie sich nach einem günstigen Ort für ihren Ordenskomplex umsahen ${ }^{89}$.

Nach dem Angriff vom Jahre 1591 wurden sich die Kalvinisten und Lutheraner ihrer unsicheren Situation bewusst und entschieden sich, die Kirche Bróg nicht zu erneuern, sondern sie nach Aleksandrowice, ein Dorf nahe bei Krakau, zu verlegen ${ }^{90}$. Das Dorf gehörte nämlich ihrem Wohltäter Stanisław Iwan Karniński ${ }^{91}$. Die protestantische Kirche in Aleksandrowice befand sich allerdings etwa $15 \mathrm{~km}$ weit vom Krakauer Stadtzentrum entfernt. Das Grundstück in der St.-Johann-Straße behielten sie jedoch bis zum Jahre 1624, als es der Orden der Bernhardiner erhielt. Anfang der dreißiger Jahre des 17. Jahrhunderts wurde dann mit dem Bau der Kirche der Unbefleckten Empfängnis Mariae begonnen ${ }^{92}$.

krakowskiego, S. 93. Zu den langfristigen Tendenzen der Religionspolitik von Sigismund III. s.: Leitsch, Das Leben am Hof, 2, S. 740-750.

89 Der Versuch, solche Gerüchte zu widerlegen, in: Ks. Jana Wielewickiego S. J. Dziennik, S. 102.

90 „Widząc tedy całe zgromadzenie krakowskie, że w swoich dolegliwościach i tak wielkich krzywdach słusznej u zwierzchności żadnej nie mogą dojść sprawiedliwości [...] bacząc oraz, że przywileje królewskie i Rzeczypospolitej sancita nic nie pomagają, trudno sobie lepszych mając obiecować albo spodziewać się czasów: Consultum być wszyscy uznali tantae rabiei nieprzyjaciół, którym zbór ten i dom chwałej Bożej był prawie sudes in oculis, ustępując cale $\mathrm{z}$ miasta Krakowa zbór przenieść sub patrocinium, którego pobliższego z ichmciów panów patronów kościoła ewangelickiego“: Kronika zboru ewangelickiego krakowskiego, S. 93.

91 Ausführlich zu seiner Persönlichkeit: H. Kowalska, Karniński Stanisław Iwan, in: Polski słownik biograficzny, 12 (1966-1967), S. 70-72.

92 Das Erbauen von katholischen Kirchen an den Stellen, an denen sich früher protestantische Gebetshäuser befanden, kam in Mitteleuropa in der Zeit der Gegenre- 


\section{FAZIT}

Wenn man die einzelnen religiös motivierten Auseinandersetzungen in Krakau näher untersucht, wird einem klar, dass die verfeindeten Konfessionen unterschiedliche Strategien wählten und auch von unterschiedlichen Gesellschaftsschichten angeregt und getragen wurden. Bei den Protestanten provozierten eindeutig vorwiegend Männer aus der mittleren Adelsschicht die Streitereien, wobei sie ihre Gegner mit Hilfe ihrer Diener angriffen. In der Regel versuchten sie, ihre persönlichen Feinde oder bekannte Vorkämpfer der Gegenreformation mit Gewalt einzuschüchtern ${ }^{93}$. Manchmal verprügelten sie auch Personen, die sich einfach zu falscher Zeit an einem falschen Ort befanden, wie zum Beispiel katholische Geistliche, die ihren Weg spät am Abend kreuzten oder in einer Kirche beteten, wo gerade der protestantische Adelige hinzukam.

Die Katholiken griffen auch ihre persönlichen Widersacher wie zum Beispiel bekannte Prediger an ${ }^{94}$, aber unverhältnismäßig öfter richtete sich ihr Hass gegen sakrale Orte der Protestanten. Mit einer solchen Taktik erzielten sie auch dauerhafte Ergebnisse, indem sie zuerst das Abhalten von protestantischen Gottesdiensten erschwerten,

formation oft vor. Beispiele aus Böhmen behandelte: J. Hrdlička, Víra a moc. Politika, komunikace a protireformace v předmoderním městě (Jindřichi̊v Hradec 1590-1630), (2013), S. 250-252.

93 Neben den schon erwähnten Vorfällen aus den siebziger und achtziger Jahren des 16. Jahrhunderts sind mehrere Angriffe auf den jesuitischen Prediger Piotr Skarga zu erwähnen: Tazbir, Piotr Skarga, S. 59; ders., Szlachta, S. 110-111.

94 Die katholischen Angriffe an die Personen wurden jedoch erst in den neunziger Jahren des 16. Jahrhunderts häufiger, als die protestantischen Kirchen vom Stadtzentrum Krakaus verschwanden. Am 5. Mai 1593 wurde zum Beispiel das Haus des protestantischen Goldschmieds Janos Kalay ausgeraubt: Materialy do dziejów reformacji, Nr. 256-258, S. 187-191. Faust Socyn, ein bekannter arianischer Theologe, wurde zweimal angegriffen - im Jahre 1594 und abermals 1598: Materiały do dziejów reformacji, Nr. 263 u. 268-271, S. 197 u. 200-206. Jakub Wolfius, der Prediger des nach Aleksandrowice übertragenen Gebetshauses, wurde wiederum im Oktober 1597 von Krakauer Studenten verprügelt: Kronika zboru ewangelickiego krakowskiego, S. 95. 
eine kostspielige Wiedereinrichtung der Gebetshäuser nötig machten und letztendlich die protestantischen Kirchen aus dem Stadtzentrum Krakaus verdrängten. Eine solche Zielausrichtung ist bemerkenswert, weil anfangs manche von der katholischen Seite provozierten Tumulte auf den ersten Blick als ganz zufällig entstanden erscheinen. Während viele katholische Teilnehmer aus den niederen Volksschichten wahrscheinlich tatsächlich keine festen Pläne hatten und spontan handelten, besprachen die Studenten ihre Absichten vorher wohl mit den Professoren und legten in Übereinstimmung mit ihnen günstige Termine und geeignete Ziele zum Losschlagen fest ${ }^{95}$. In den siebziger und achtziger Jahren des 16. Jahrhunderts waren es vorwiegend die Professoren der Krakauer Akademie, von denen einige als Priester der Marienkirche dienten, welche zu den Unruhen mit beitrugen. Seit Ende der achtziger Jahre traten noch zwei weitere aktive Gruppen dazu, nämlich die Jesuiten mit ihren Schülern, sowie Bruderschaften, die sich in dieser Zeit etablierten und von verschiedenen Orden sowie von Kanonikern der Marienkirche beeinflusst wurden ${ }^{96}$.

Korekturgelesen von Dirk Rosenstock

\section{RYWALIZACJA MIĘDZY KATOLIKAMI I PROTESTANTAMI O KRAKOWSKIE CENTRUM W DRUGIEJ POŁOWIE XVI WIEKU}

\section{(STRESZCZENIE)}

W artykule przeanalizowano rywalizację różnych wyznań o wpływ na przestrzeń miasta królewskiego Krakowa. Przede wszystkim zwrócono uwagę na konflikty siłowe oraz na przyjmowane strategie. Podczas gdy protestanci atakowali często pojedyncze osoby, z reguły bardzo zaangażowane w kontrreformację, katolicy próbowali raczej

95 Einen solchen Verdacht erhob zum Beispiel der Arianer Mikołaj Kazimierski am 24. September 1591 in der Adelsversammlung in Radom aus. Materiały do dziejów reformacji, Nr. 234, S. 173.

96 Tazbir, Piotr Skarga, S. 207-208. 
wywołać tumulty, w ramach których niszczono świątynie innowierców. Ta ostatnia taktyka okazała się bardzo skuteczna i doprowadziła do wyparcia protestantów na początku lat 90-tych XVI wieku z centrum miasta.

Tłumaczenie

Renata Skowrońska

\section{DAS WETTEIFERN ZWISCHEN KATHOLIKEN UND PROTESTANTEN UM DAS KRAKAUER STADTZENTRUM IN DER ZWEITEN HÄLFTE DES 16. JAHRHUNDERTS}

\section{(ZUSAMMENFASSUNG)}

In der Studie werden die Rivalitäten der Konfessionen auf dem Gebiet der Königsstadt Krakau untersucht. Im Fokus stehen dabei vornehmlich die gewaltsamen Konflikte und die bei diesen Auseinandersetzungen gewählten Strategien. Während die Protestanten oft einzelne Personen, meist Vorkämpfer der Gegenreformation, angriffen, versuchten die Katholiken eher Tumulte auszulösen, in deren Verlauf ein Sakralort der Andersgläubigen zerstört wurde. Diese Taktik erwies sich schließlich als sehr erfolgreich, denn am Anfang der neunziger Jahre des 16. Jahrhunderts führte sie zur Verdrängung der Protestanten aus dem Stadtzentrum.

\section{RIVALRY BETWEEN CATHOLICS AND PROTESTANTS CONCERNING CRACOW IN THE SECOND HALF OF THE 16TH CENTURY}

\section{(SUMMARY)}

The article analyzes the competition among various denominations to exert influence on the space of the royal city of Cracow. First of all, the author underlined forceful conflicts and strategies adopted. While Protestants attacked very often individual people involved in the Counterreformation, Catholics preferred to give rise to tumult, which led to the destruction of the temples of dissenters. The latter strategy turned out to be very effective and led to the displacement of Protestants at the beginning of the 1590 s from the city centre. 


\section{Słowa kluczowe / Schlagworte / Keywords}

- Kraków; konfesjonalizacja; katolicy i protestanci; siłowe konflikty wyznaniowe; jezuici

- Krakau; Konfessionalisierung, Katholiken und Protestanten; gewaltsame konfessionelle Konflikte; Jesuiten

- Cracow; confessionalisation; Catholics and Protestants; forceful religious conflicts; Jesuits

\section{BIBLIOGRAFIA / BIBLIOGRAFIE / BIBLIOGRAPHY}

\section{ŹRÓDłA ARCHIWALNE / ARCHIVALISCHE QUELLEN / ARCHIVAL SOURCES}

Státní oblastní archiv Třeboň, Historica Třeboň, Urkunden, Briefe sowie Zeitungen und Berichte der Herren von Rosenberg.

\section{ŹRÓDłA DRUKOWANE / GEDRUCKTE QUELLEN / PRINTED SOURCES}

Der Briefwechsel der Schweizer mit den Polen, hg. v. T. Wotschke, (Archiv für Reformationsgeschichte, Ergänzungsband 3, 1908).

I. A. Caligarii nuntii apostolici in Polonia epistolae et acta 1578-1581, hg. v. L. Boratyński, (1915).

Jacobi Franci Relatio historica quinquennalis. Wahrhafftige Beschriebung aller fürnemmen unnd gedenckwürdigen Geschicht, so sich innerhalb funff Jahren, nemlich, vom Anno 1590 biß 1595 zugetragen haben, (1595).

Konfederacja warszawska 1573 roku, wielka karta polskiej tolerancji, hg. v. M. Korolko, J. Tazbir, (1980).

Kronika mieszczanina krakowskiego z lat 1575-1595, hg. v. H. Barycz, (1930).

Kronika zboru ewangelickiego krakowskiego, w której erekcja zboru tego, przywileje, kaznodzieje albo słudzy Boży, starsi zborowi, różne prześladowania, zboru zburzenia, $i$ wiele innych pamiętnych rzeczy przypominaja się i opisuja. Przez X. Wojciecha Węgierskiego, hg. v. M. Pawelec, (2007).

Ks. Jana Wielewickiego S. J. Dziennik spraw domu zakonnego OO. Jezuitów uś. Barbary w Krakowie od r. 1579 do r. 1599 (włacznie), hg.v.J. Szujskij,(1881). Materiały do dziejów reformacji w Krakowie. Zaburzenia wyznaniowe w latach 
1551-1598, hg. v. R. Żelewski, (Materiały Komisji Nauk Historycznych 6, 1962).

Skarga P., Upominanie do ewángelikow y inych niekátholikow, $z$ strony zboru

Krákowskiego, zburzonego roku Pánsk. 1591, in: ders., Kazania o siedmi Sakramentach, (1600).

Świętosława Orzelskiego Bezkrólewia ksiagg ośmioro 1572-1576, hg. v. E. Kuntze, (Scriptores rerum Polonicarum 22, 1917).

Uchańsciana czyli Zbiór dokumentów, wyjaśniajacych życie i działalność Jakóba Uchańskiego arcybiskupa gnieznieńskiego, legata urodzonego, Królestwa Polskiego prymasa i pierwszego księcia, 1581, hg. v. T. Wierzbowski, 3 (1890).

\section{LITERATURA / LITERATUR / LITERATURE}

Augustynowicz Ch., Die Kandidaten und Interessen des Hauses Habsburg in Polen-Litauen während des zweiten Interregnums 1574-1576, (2001).

Barycz H., Geneza i autorstwo „Equitis poloni in iesuitas actio prima“ (studjów nad polemikq antyjezuicka $w$ Polsce część 1), (1934).

Barycz H., Historia Uniwersytetu Jagiellońskiego w epoce humanizmu, (1935).

Besala J., Stefan Batory, (1992).

Cavanaugh W., Myth of Religious Violence. Secular Ideology and the Roots of Modern Conflict, (2009).

Długosz-Kurczabowa K., Konfesja Sandomierska, (2001).

Dybkowska A., Zygmunt August, (2003).

Dzięgielewski J., Jak i dlaczego powstał wizerunek Zygmunta III Wazy jako władcy nietolerancyjnego?, „Miscellanea Historico-Archivistica“, 23 (2016), S. $153-161$.

Dzięgielewski J., Prymasi $w$ roli interreksów, in: Prymasi i prymasostwo $w$ dziejach państwa i narodu polskiego, hg. v. W. J. Wysocki, (2002), S. 39-50.

Gołaszewski Z., Bracia polscy, (2005).

Hanik M., Trzy pokolenia $z$ rodu Bonerów, (1985).

Hrdlička J., Víra a moc. Politika, komunikace a protireformace $v$ předmoderním městě (Jindřichìv Hradec 1590-1630), (2013).

Hryniewicz I., Wołanie na tumult. Prolegomena do badań nad przemoca $w$ stosunkach międzywyznaniowych w Rzeczypospolitej w XVI i XVI wieku, „Acta Universitatis Lodziensis. Folia Litteraria Polonica“, 21 (2013), S. 67-95.

Kaniewska I., Żelewski R., Urban W., Studia z dziejów młodzieży Uniwersytetu Krakowskiego $w$ dobie Renesansu, (1964). 
Kawecka-Gryczowa A., Les imprimeurs des antitrinitaires polonais Rodecki et Sternacki. Histoire et bibliographie, (1974).

Kempa T., Konflikty wyznaniowe w Wilnie od poczatki reformacji do końca XVII wiek, (2016).

Koslofsky C., Honour and Violence in German Lutheran Funerals in the Confessional Age, „Social History“, 20 (1995), S. 315-337.

Kowalska H., Karniński Stanisław Iwan, in: Polski słownik biograficzny, 12 (1966-1967), S. 70-72.

Leitsch W., Das Leben am Hof König Sigismunds III. von Polen, 2. Bd. (2009).

Lepszy K., Stefan Batory a Gdańsk, ,Rocznik Gdański“, 4 (1932), S. 2-56.

Merczyng H., Zbory i senatorowie protestanccy, (1904).

Müller M. G., Der Consensus Sendomirensis - Geschichte eines Scheiterns? Zur Diskussion über Protestantismus und protestantische Konfessionalisierung in Polen-Litauen im 16. Jahrhundert, in: Konfessionelle Pluralität als Herausforderung. Koexistenz und Konflikt in Spätmittelalter und Früher Neuzeit, hg. v. J. Bahlcke (u. a.), (2006), S. 397-408.

Obirek S., Działalność kulturalna jezuitów w Rzeczypospolitej Obojga Narodów (1564-1668). Próba syntezy,(1996).

Obirek S., Jezuici na dworach Batorego i Wazów 1580-1668. Wpływ kapelanów dworskich $i$ wychowawców książą na postawy panujących $i$ politykę państwa, (1996).

Orden und Klöster im Zeitalter von der Reformation und katholischer Reform 1500-1700, hg. v. F. Jürgensmeier, R. E. Schwerdtfeger, 1 (2005).

Pirożyński J., Winkelzüge und Fälschungen in der Praxis der Krakauer Buchdrucker des 16. und 17. Jahrhunderts, in: Studien und Essays zur Druckgeschichte. Festschrift für Claus W. Gerhardt zum siebzigsten Geburtstag, hg. v. R. Münch, (1997), S. 89-97.

Po-chia Hsia R., The World of Catholic Renewal 1540-1770, (1999).

Pražáková K., Konfesní nepokoje v Krakově pohledem rožmberského zpravodajství, „Folia historica Bohemica“, 30, 1 (2015), S. 5-32.

Pražáková K., Obraz Polsko-litevského státu a Ruska ve zpravodajství české šlechty (1450-1618), (2015).

Pražáková K., T. Sterneck T., „Rychlejší než větry, hbitější než všichni zajíci“. Útěk Jindřicha $z$ Valois $z$ Polska v pamfletu $z$ roku 1574, „Slovanský přehled“, 100, 3 (2014), S. 473-497.

Przybyliński R., Hetman wielki koronny Mikołaj Mielecki (ok. 1540-1585), (2002). 
Serwański M., Henryk III Walezy. Stosunki polsko-francuskie w latách 1566-1576, (1976).

Schramm G., Der polnische Adel und die Reformation, (1965).

Schramm G., Ein Meilenstein der Glaubensfreiheit. Der Stand der Forschung über Ursprung und Schicksal der Warschauer Konföderation von 1573, „Zeitschrift für Ostforschung"', 24 (1975), S. 711-736.

Sucheni-Grabowska A., Zygmunt August. Król polski $i$ wielki książę litewski, (2010).

Tazbir J., Arianie i katolicy, (1971).

Tazbir J., Dzieje polskiej tolerancji, (1973).

Tazbir J., Piotr Skarga. Szermierz kontrreformacji, (1962).

Tazbir J., Reformacja, kontrreformacja, tolerancja, (1997).

Tazbir J., Szlachta i teologowie. Studia z dziejów polskiej kontrreformacji, (1987). Wisner H., Zygmunt III. Waza, (1991).

Z dziejów Kleparza. W 600 rocznice nadania praw miejskich przez Króla Kazimierza Wielkiego, (1968).

Załęski S., Jezuici w Polsce, 1: Walka z różnowierstwem 1555-1608, (1906).

Żelewski R., Akta i relacje dotyczace zburzenia zboru kalwińsko-luterańskiego w Krakowie w r. 1574, ,Teki archiwalne“, 2 (1954), S. 109-137. 